\title{
A PESQUISA ESCOLAR COMO INSTRUMENTO PEDAGÓGICO: UM DOS CAMINHOS PARA AMPLIAR AS SITUAÇÕES DIDÁTICAS DA EDUCAÇÃO FÍSICA ESCOLAR NO ENSINO FUNDAMENTAL
}

\author{
Jorge Luis D"Avila \\ Universidade Federal do Mato grosso do Sul, Campo Grande, Mato Grosso do Sul, \\ Brasil
}

\section{Christiane Martins Fernandes}

Universidade Federal do Mato grosso do Sul, Campo Grande, Mato Grosso do Sul, Brasil

\begin{abstract}
Resumo
Este ensaio discute a respeito de uma prática pedagógica que tem como objeto a pesquisa, considerada como um instrumento para auxiliar no processo de ensinoaprendizagem da Educação Física Escolar. Esse instrumento, se bem orientado, dá concretude e expressa a totalidade do corpo teórico/prático da disciplina em questão, contribui para que crianças e jovens aprendam os conteúdos, de forma participativa, compreendendo a realidade e produzindo conhecimentos. Para isso, é necessário conhecer o seu significado e buscar o entendimento de como orientar a pesquisa em sala de aula, evitando concepções equivocadas que podem diminuir as chances desse tipo de atividade alcançar seus objetivos.
\end{abstract}

Palavras chave: Educação Física Escolar. Pesquisa como Instrumento Pedagógico. Ensino Fundamental.

\section{Introdução}

A Educação Física Escolar é compreendida como a área do conhecimento que trata da cultura corporal. Seu corpo teórico/prático deve ser oferecido ao aluno para o desenvolvimento de sua consciência crítica, de forma a oportunizar a sua compreensão e intervenção na realidade, buscando por meio do conhecimento, uma possível transformação social.

Importante destacar que, apesar da variedade temática presente nesta área, é observada na prática de alguns professores a supremacia desportiva com ênfase na aptidão física. Tal realidade não condiz com o que está refe- 
rendado nos Parâmetros Curriculares Nacionais (PCN), onde consta que a Educação Física Escolar

[...] pode sistematizar situações de ensino e aprendizagem que garantam aos alunos o acesso a conhecimentos práticos e conceituais. Para isso é necessário mudar a ênfase na aptidão física e no rendimento padronizado que caracterizava a Educação Física, para uma concepção mais abrangente, que contemple todas as dimensões envolvidas em cada prática corporal. (BRASIL, 1997, p. 24).

De acordo com o documento supracitado, o docente, em seu fazer pedagógico, deve distinguir os objetivos desse componente curricular dos objetivos profissionais do esporte, da dança, da ginástica e da luta. Sua prática deve ser encaminhada para o desenvolvimento da potencialidade dos alunos " [...] de forma democrática e não seletiva, visando seu aprimoramento como seres humanos [...]” (BRASIL, 1997, p. 24).

Desta forma, para que isso ocorra, a Educação Física Escolar deve conduzir o aluno a reflexões críticas sobre a cultura corporal. O professor deve compreender que mais importante do que as aptidões físicas é o desenvolvimento das análises pedagógicas a respeito de valores como solidariedade, cooperação e expressão de movimentos, mostrando ao educando que pular, correr, saltar, jogar, nadar, e outras habilidades, não são inatas do ser humano, mas que foram sendo constituídas historicamente para superar as dificuldades da humanidade.

Nesse sentido, esse artigo tem o propósito de discutir a respeito de uma prática pedagógica que tem como eixo norteador a pesquisa, considerada como um instrumento para auxiliar no processo de ensino-aprendizagem da Educação Física Escolar.

A nosso ver, a utilização desta, se bem orientada, dá concretude e expressa a totalidade do corpo teórico/prático da disciplina em questão, contribuindo para que crianças e jovens aprendam os conteúdos ou assuntos abordados, de forma participativa, compreendendo a realidade e produzindo conhecimentos.

Vale expor que o mundo globalizado está em constante transformação, e isso deve provocar nos docentes reflexões acerca do processo pedagógico, com o intuito de buscar caminhos que propiciem ao aluno efetivas condições para a aprendizagem. Dentre esses caminhos, podemos citar a busca, em diferentes metodologias de ensino, das que de fato consigam oferecer ao educando uma aprendizagem com significado para sua vida, possibilitando-o associar os conhecimentos apreendidos na escola ao seu cotidia- 
no. Por isso, cabe aqui pontuar que não basta ao aluno receber informações por meio da transmissão dos conteúdos, pois o mais importante é que ele receba subsídios para que estas se convertam em conhecimento.

Para tanto, é indispensável que os professores conheçam o significado de uma prática por meio da pesquisa, e busquem, através de uma fundamentação teórica, o entendimento de como orientá-la em sala de aula, evitando concepções errôneas que diminuirão as chances desse tipo de atividade alcançar seus objetivos.

\section{Pesquisa: considerações e conceitos para sua utilização nas aulas de Educação Física Escolar.}

Ao escolher a pesquisa escolar para subsidiar a Educação Física, buscamos provocar uma reflexão que sirva ao professor como um instrumento pedagógico capaz de induzir o aluno à investigação, à busca de informações para convertê-las em conhecimento. Isso se dará por meio da elaboração de argumentos que tornem o aluno capaz não somente de realizar práticas corporais, mas também de aprender para compreender seu próprio meio e o mundo à sua volta.

Importante mencionar que a Lei de Diretrizes e Bases da Educação, Lei n.9394/96 (LDB) no Título II "Dos Princípios e Fins da Educação Nacional", art. $3^{\circ}$, destaca alguns princípios em que o ensino será ministrado. Como um deles, o caput II do referido artigo, destaca a "[...] liberdade de aprender, ensinar, pesquisar e divulgar a cultura, o pensamento, a arte e o saber; [...]", enfatizando o uso da pesquisa como uma das estratégias de ensino para propiciar ao aluno a aquisição de conhecimentos.

Outra questão relevante é que os Parâmetros Curriculares Nacionais (BRASIL, 1997), na sua introdução, apresentam como um dos objetivos do ensino fundamental que os alunos sejam capazes de "[...] saber utilizar diferentes fontes de informação e recursos tecnológicos para adquirir e construir conhecimentos" (BRASIL, 1997, p. 69). O documento aborda também que "[...] é importante considerar que o livro didático não deve ser o único material a ser utilizado, pois a variedade de fontes de informação é que contribuirá para o aluno ter uma visão ampla do conhecimento" (BRASIL, 1997, p.67).

Diante disso, faz-se necessário que o docente entenda que não existe somente a quadra esportiva como um espaço para a aprendizagem. Sendo assim, ele deve oferecer aos alunos o maior número possível de locais em que estes possam ler, pesquisar, selecionar as informações relevantes para o conteúdo ou tema em estudo, a fim de que se apropriem de novos saberes.

Pensar a Prática, Goiânia, v. 17, n. 2, p. 331-343, jan./mar. 2014 333 
De acordo com Libâneo (2005), as pessoas na atualidade aprendem em diferentes lugares, como na televisão, nos vídeos, no computador, ampliando cada vez mais os ambientes de aprendizagem. Isso significa dizer que os professores não podem propiciar apenas uma única fonte de investigação, e sim aproveitar todos os espaços utilizados pelos educandos.

Nesse sentido, o docente, ao abordar, por exemplo, o conteúdo dança deve compreender que seu ensino perpassa as quadras de esporte. Isso implica ao professor a busca por outros espaços pedagógicos para que o conhecimento sobre a dança seja efetivado.

Sendo assim, o docente, por meio da prática da pesquisa e da mediação no momento da construção dos argumentos necessários à compreensão do objeto de estudo - neste caso, a dança - fará com que os alunos se mobilizem para encontrar informações acerca do mesmo. Dessa maneira, quando o aluno questiona o conceito de dança, precisa se movimentar para responder às dúvidas suscitadas no início da investigação. A partir do questionamento será trilhado o caminho para a consulta em bibliografias, em documentários, entrevistas com especialistas, dentre outras fontes relevantes. Daí em diante, os educandos iniciam a elaboração de novas compreensões sobre a dança. E por fim, conforme avançam essas compreensões, o docente solicitará que os alunos, em algum tipo de produção, apresentem o que aprenderam sobre o conteúdo. Após essa produção, o conhecimento adquirido será validado mediante a exposição para o grupo de colegas da sala de aula.

Cabe enfatizar também que a pesquisa está proposta nos PCN da Educação Física Escolar. Como exemplo, abaixo, seguem dois trechos retirados desse documento:

Os conteúdos são amplos, diversificados e podem variar muito de acordo com o local em que a escola estiver inserida. Sem dúvida alguma, resgatar as manifestações culturais tradicionais da coletividade, por intermédio principalmente das pessoas mais velhas é de fundamental importância. A pesquisa sobre danças e brincadeiras cantadas de regiões distantes, com características diferentes das danças e brincadeiras locais, pode tornar o trabalho mais completo. [...] (BRASIL, 1997, p. 39 grifo nosso).

Nesse sentido, o professor pode questionar a forma como os meios de comunicação apresentam padrões de beleza, saúde, estética, bem como aspectos éticos. Assim, pode, por exemplo, fazer leituras dos cadernos esportivos e discutir termos como 'inimigos', 'guerra', 'batalha de mor-

Pensar a Prática, Goiânia, v. 17, n. 2, p. 331-343, jan./mar. 2014 334 
te', que são empregados para descrever jogos entre dois times ou seleções e quais as implicações dessa utilização.

Pode também pesquisar os tipos físicos em evidência nas propagandas, novelas, etc., e sua relação com o consumo de produtos e serviços. (BRASIL, 1997, p. 63grifo nosso).

Os trechos acima consideram a importância do processo investigativo e do docente que mediará seu percurso, propiciando momentos para que o educando questione, elabore argumentos, e comunique os resultados da pesquisa, o conhecimento.

Ao mencionarmos a presença da pesquisa na LDB e também nos PCN, nos remetemos ao pensamento de que a escola e o docente devem se utilizar da pesquisa em sala de aula para oportunizar a aprendizagem ao aluno. Contudo, essa prática comumente é empregada apenas como um instrumento para obtenção de nota para a disciplina, sem orientação e mediação ao longo do processo.

Isso pode ocorrer devido a alguns empecilhos, tais como a ausência de compreensão do professor sobre pesquisa, tendo em vista a possível carência dessa prática na sua formação inicial e/ou em todo o seu processo de escolarização. Nesse sentido, podemos inferir que muitos professores, ao passarem pela escola, aprenderam por meio de um modelo de ensino tradicional, "[...] 'bancário', que deforma a necessária criatividade do educando e do educador [...]" (FREIRE, 1996, p.13).

Nessa mesma linha de pensamento, Ninin afirma que:

Os professores, muitas vezes conduzidos por crenças em práticas educacionais que viveram quando estudantes e por processos de formação docente que privilegiaram discussões sobre estratégias de ensino pautadas na transmissão do conhecimento e no poder da quantidade de informações, vêem-se despreparados para orientar seus alunos em relação à tarefa de pesquisar [...] $(2008$, p.7)

Saviani (2009) explicita que a proposta do ensino tradicional era transmitir os conhecimentos obtidos pela ciência, sistematizados, pertencentes ao acervo cultural da humanidade. Explica, ainda, que esse tipo de ensino tinha como centro do processo educativo, o professor, os conteúdos estruturados e organizados dentro de uma lógica.

Para Amaral e Lima:

Pensar a Prática, Goiânia, v. 17, n. 2, p. 331-343, jan./mar. 2014 335 
[...] a prática pedagógica centrada no professor, preocupada com a transmissão de conhecimentos para vencer os conteúdos programáticos, utilizando-se somente de aulas expositivas, fornecendo materiais teóricos prontos com exercícios para serem respondidos e exigidos em provas ainda é presença marcante na sala de aula. (2011, p. 41):

Para que o docente possa utilizar uma prática pedagógica que auxilie o aluno na produção do conhecimento, faz-se necessária a compreensão sobre a importância da pesquisa na quadra/sala de aula como um instrumento para a aprendizagem. Para tanto, é importante a apreensão dos conceitos da pesquisa, a fim de que o professor possa efetivamente orientá-la em sala de aula.

Bagno (2007, p. 17) entende que pesquisa é "[...] procurar, buscar com cuidado; procurar por toda a parte; informar-se; inquirir; perguntar; indagar bem, aprofundar na busca". Nesse sentido, ao ser desenvolvida com os alunos em sala de aula, a pesquisa permitirá ir além da cópia e da leitura de um único livro didático, fazendo com que os alunos se aprofundem na busca por diferentes fontes de informação. Isso ocasionará no conhecimento do objeto de estudo.

Gatti (2002) destaca que a pesquisa é o caminho para se apropriar de conhecimentos sobre algum assunto. Para a autora, a pesquisa é:

$\mathrm{O}$ ato pelo qual procuramos obter conhecimento sobre alguma coisa. [...] Contudo, num sentido mais estrito, visando a criação de um corpo de conhecimentos sobre um certo assunto, o ato de pesquisar deve apresentar certas características específicas. Não buscamos, com ele, qualquer conhecimento, mas um conhecimento que ultrapasse nosso entendimento imediato na explicação ou na compreensão da realidade que observamos. (GATTI, 2002, p. 9-10)

Desse modo, as atividades de pesquisa oportunizarão que o aluno, a partir da seleção das informações acerca do tema ou conteúdo apresentado em sala de aula, construa argumentos que superem as ideias que estavam no senso comum.

Nicolini (2005, p. 54) coloca que "[...] a pesquisa é o caminho para se ensinar a interpretar, pois os alunos têm que aprender a realizar leituras, reconhecer e construir suas próprias interpretações”. Essa busca em leituras diversas contribuirá para que o educando interprete diferentes posiciona- 
mentos dos autores lidos, para, assim, chegar a uma nova verdade, a um novo conhecimento.

Filho e Nunes (1999) afirmam que a finalidade da pesquisa na educação básica é a de ampliar ou enriquecer o conhecimento do aluno. Contudo, para que isso aconteça é fundamental desmistificar seu conceito e pontuar algumas orientações necessárias a serem conduzidas em sala de aula, visto que, ao utilizar a pesquisa como instrumento pedagógico, os docentes precisam ter a clareza da sua complexidade para não confundir o educando e fazer com que este tenha uma compreensão simplista do que seja pesquisar.

Podemos expressar essa preocupação, pois, se o docente não orientar o processo investigativo, o aluno apenas consultará algum texto em livros ou na Internet e o copiará, sem interpretar e analisar as diferentes informações encontradas sobre o que está investigando. Diante disso, Lüdke (2009) argumenta que esse tipo de busca de informações desperta a curiosidade dos alunos, mas não podemos dizer que seja uma atividade de pesquisa, e sim, uma simples atividade de consulta.

Ninin cita que:

[...] muitos professores em relação à atividade de pesquisa resumem-se, ainda, nos dias de hoje, a oferecer aos alunos um roteiro contendo: uma data para entrega do trabalho; a solicitação dos nomes dos alunos integrantes do grupo; a indicação das partes que o trabalho deve conter, como, por exemplo, introdução, objetivo, justificativa, desenvolvimento, bibliografia; a indicação dos conteúdos a serem pesquisados; além de algumas dicas orientadoras, como, por exemplo, "não faça cópia de trechos de livros", "a entrega do trabalho fora do prazo implica diminuição na nota", entre outras. (2008, p.3, grifo do autor)

Segundo Ninin (2008), quando as atividades de pesquisa são conduzidas dessa forma, não desencadeiam o pensamento crítico dos educandos, visto que o professor não propicia ambientes para que estes discutam seus pontos de vista e apresentem suas argumentações frente ao que estão descobrindo.

Para que seja considerado o processo de construção e não apenas o produto da pesquisa, ou seja, o resultado final, o docente deverá orientar o percurso da aprendizagem desde a etapa da escolha do assunto até o momento da comunicação dos resultados da investigação. Compreendemos, então, a complexidade que o trabalho em sala de aula com pesquisa impõe ao 
professor de Educação Física, tendo em vista que este não se resume a reprodução, a atividades sem prévia orientação.

É importante pontuar que a trajetória da pesquisa, segundo Moraes; Galiazzi; Ramos (2004, p. 12) envolve três momentos principais, que são: "[...] o questionamento, a construção de argumentos e a comunicação". Em relação ao questionamento, os autores mencionam que:

Para que algo possa ser aperfeiçoado, é preciso criticá-lo, questioná-lo, perceber seus defeitos e limitações. É isto que possibilita pôr em movimento a pesquisa em sala de aula. O questionar se aplica a tudo que constitui o ser, quer sejam conhecimentos, atitudes, valores, comportamentos e modos de agir. (2004, p.12)

Assim, o processo da pesquisa escolar inicia-se com as indagações dos alunos, a curiosidade, o interesse em encontrar respostas sobre o desconhecido. Esse momento permite que o educando se envolva e, acima de tudo, faz com que o professor perceba o que precisa ser aprendido. Dessa forma, é possível levantar, ler e organizar previamente as fontes de informações a serem consultadas, para que o aluno construa argumentos (MORAES et. al, 2004) acerca do assunto abordado.

Esse processo de busca que segue o questionamento é o segundo momento da pesquisa em sala de aula. De acordo com MORES et. al (2004, p. 16), esta é a fase da construção de argumentos. Nessa fase, o aluno terá condições de ampliar seu conhecimento a partir do que já conhecia sobre o objeto de estudo. Por isso, é de extrema importância o envolvimento do professor, pois geralmente os alunos que estão nos anos finais do ensino fundamental ainda não possuem maturidade suficiente para trilhar sozinhos o caminho dessa busca.

Nesse processo de coleta de informações, o docente oportunizará o desenvolvimento da autonomia do educando, tendo em vista que este precisará se responsabilizar também por essa busca, ou seja, não permanecerá somente à espera de instruções do professor.

Dessa forma, ao introduzir um novo estudo corporal torna-se relevante diagnosticar o que o educando sabe ou ouviu falar sobre ele. Esse diagnóstico permitirá ao professor conhecer as dúvidas de seus alunos, suas inquietações e o que eles ainda não sabem sobre o assunto tratado.

Vale mencionar que o aprendiz questiona a partir do que ele já conhece. Isso significa que ele possui conhecimentos prévios sobre o que the está sendo apresentado. O aluno, ao chegar à escola, à sala de aula, leva consigo informações e conhecimentos apreendidos em diversos locais que po- 
dem ser de senso comum, vindos da experiência cotidiana ou associados com outros conhecimentos que não precisam ser necessariamente científicos ou escolares (HERNÁNDEZ, 1998).

Dessa maneira, quando o docente abordar, por exemplo, o tema "dança", o aluno apresentará um conhecimento prévio sobre ela, sobre suas manifestações culturais, seus ritmos, formas de dançar, entre outros, que ouviu em um noticiário de televisão e/ou nas conversas com as pessoas da sua comunidade ou em outros lugares. De acordo com a abordagem do professor acerca do assunto, o aluno levantará questões que o permitirão estabelecer e/ou ampliar aquilo que precisa ser pesquisado. Com isso, o docente poderá encaminhar e fazê-los buscar diversas fontes de pesquisa como textos, vídeos, atividades em campo, entrevistas com professores de dança, entre outras, para a coleta de informações anteriormente desconhecidas (ou não) sobre o assunto.

A busca bem orientada produzirá a construção de argumentos por meio de conexões com diversas leituras, pessoas e/ou locais que possam trazer ideias, pontos de vista diferentes e novas interpretações sobre o objeto de estudo.

Conforme MORAES et.al, essas interpretações (ou novas hipóteses sobre um problema) apresentadas pelos alunos precisam ser fundamentadas, para "[...] convencer os outros. Isso implica diversificadas atividades que incluem o ler, o discutir, o argumentar, o reunir dados, analisá-los e interpretálos. Isso pode tanto dar-se em nível individual como de grupo". (MORAES et.al, 2004, p.16).

No decorrer da construção dos argumentos relacionados ao objeto de estudo, o docente orienta os alunos para uma produção, seja por meio de um texto, de uma discussão em grupo, de uma dramatização, por um vídeo elaborado por eles, entre outros meios que expressem a validação desses argumentos em sala de aula.

Para esclarecer essa ideia, Moraes et.al, (2004, p.17) coloca um exemplo a partir de um assunto a ser estudado:

[...] se questionamos o conceito de ácido, precisamos movimentarmo-nos para responder ao nosso questionamento. Podemos consultar bibliografias, podemos falar com pessoas que entendem do assunto, podemos investigar o que outros pensam sobre ácidos. A partir disso vamos elaborando novas compreensões sobre ácidos, vamos estruturando novos argumentos sobre o que são, suas propriedades, suas reações. Finalmente, à medida que avançamos, começamos a colocar tudo isso em uma produção concreta $[\ldots]$.

Pensar a Prática, Goiânia, v. 17, n. 2, p. 331-343, jan./mar. 2014 
Em seguida à apresentação do que foi construído por meio da coleta de informações, inicia-se, segundo os autores acima citados, a comunicação do processo de pesquisa que será posto à crítica dos envolvidos no processo. A submissão à crítica fará com que, se necessário for, os alunos reconstruam os argumentos apresentados. Nesse momento, eles compartilharão o produto da sua pesquisa, fazendo com que ele seja compreendido pelos ouvintes.

E essa crítica será submetida ao grupo em sala de aula, à comunidade da escola, ou a grupos maiores, o que permitirá constatar o que efetivamente foi aprendido pelo educando no decorrer do processo de investigação.

\begin{abstract}
No contexto do ensino fundamental, cabe ao professor proporcionar ao aluno um momento no qual ele possa explicar suas descobertas aos colegas, ou possibilitar-lhe a exposição de cartazes e pôsteres, a participação em feiras do conhecimento, a elaboração de um jornal escolar ou, ainda, a participação em eventos inter-escolares. (STEFANO, 2005, p. 61).
\end{abstract}

Diante dessas considerações, reforçamos que, para que o aluno aprenda por meio da pesquisa em sala de aula, o docente precisa acompanhá-lo em todos os momentos do processo investigativo, orientando, mediando e avaliando não somente sua fase final, mas todo o percurso trilhado. Para desempenhar esse papel é indispensável que o professor amplie seu conhecimento sobre a pesquisa, fazendo dela um instrumento para melhorar o trabalho pedagógico e para propiciar a aprendizagem do educando.

\title{
Considerações Finais
}

Por meio desse estudo esperamos despertar o interesse dos professores de Educação Física Escolar sobre a importância da pesquisa para a aprendizagem dos alunos, visto que, ao serem introduzidos e orientados em práticas investigativas, estes encontrarão condições para o desenvolvimento da sua autonomia, criticidade e autoria, à medida em que forem desafiados no decorrer do processo educativo.

A pesquisa, para ser efetiva, precisa do envolvimento tanto dos professores quanto dos alunos. Esses, quando são estimulados a questionar, colocam em movimento um conjunto de ações, de argumentações e reflexões que possibilita a superação do estado atual do conhecimento, do senso comum, para alcançar novos patamares do conhecer e do fazer. 
Dessa maneira, o docente, ao incluir essa prática em sala de aula/quadra de esportes, contribuirá para que os educandos compreendam o conceito de que a pesquisa é realizada por todos aqueles que buscam aprender sobre algo ainda desconhecido. E esse processo, quando bem orientado, oportunizará ao aluno questionar a realidade e assim construir argumentos para validar o conhecimento apreendido.

Nossa expectativa é de que a pesquisa permita aos alunos nas aulas Educação Física uma reflexão sobre a cultura corporal, aumentando seu leque de conhecimento, para, assim, intervir no seu cotidiano.

\title{
RESEARCH SCHOOL TEACHING AS A TOOL: ONE OF WAYS TO ENLARGE THE SITUATIONS OF TEACHING PHYSICAL EDUCA- TION IN SCHOOLS ELEMENTARY SCHOOL
}

\begin{abstract}
This essay discusses about a pedagogical practice that focuses the research, considered as a pedagogical tool to aid in the teaching and learning of physical education. This instrument is well oriented, gives concreteness and expresses the totality of the theoretical / practical discipline in question, helps children and young people learn the content in a participatory manner, understanding the reality and producing knowledge. For this it is necessary to know its meaning and seek the understanding of how to guide it in the classroom, avoiding misconceptions that may decrease the chances of this type of activity to achieve their goals.

Keywords: Physical Education. Survey Instrument as Pedagogical. Elementary School.

\section{INVESTIGACIÓN DOCENTE ESCUELA COMO HERRAMIENTA: UNA DE LAS MANERAS DE AUMENTAR LAS SITUACIONES DE ENSEÑANZA DE LA EDUCACIÓN FÍSICA EN LA ESCUELA PRIMARIA DE ESCUELAS}

\section{Resumen}

En este ensayo se discute acerca de una práctica pedagógica que se centra la investigación, considerada como una herramienta pedagógica para ayudar en la enseñanza y aprendizaje de la educación física. Este instrumento está bien orientada, da concreción y expresa la totalidad de la disciplina teórica / práctica en cuestión, ayuda a los niños y los jóvenes aprenden el contenido de una manera participativa, entendiendo la realidad y producir conocimiento. Para ello, es necesario conocer su significado y buscar la comprensión de cómo guiar en el aula,

Pensar a Prática, Goiânia, v. 17, n. 2, p. 331-343, jan./mar. 2014 
evitando malentendidos que pueden disminuir las posibilidades de este tipo de actividades para lograr sus objetivos.

Palabras-claves: La Educación Física. Encuesta Instrumento Pedagógico. La Escuela Primaria.

\section{Referências}

AMARAL, Ionara Barcellos; LIMA, Valderez Marina do Rosário. A educação pela pesquisa, o questionamento e a crítica: propostas viáveis para ensinar e aprender. Acta Scientiae. v. 13, n. 1, jan./jun. 2011. Disponível em: http://www.sumarios.org/sites/default/files/pdfs/65019_7353.PDF. Acesso em 16 de jan. de 2012.

BAGNO, M. Pesquisa na escola - o que é e como se faz. $21^{\circ}$ ed. 102 p. São Paulo, SP: Edições Loyola, 2007.

BRASIL. Lei no 9.394 de 20/12/1996. Lei de diretrizes e bases da Educação (LDB).

MEC/SEF. Parâmetros Curriculares Nacionais: introdução aos Parâmetros Curriculares Nacionais. Brasília: MEC, 1997.

MEC/SEF. Parâmetros Curriculares Nacionais: Educação Física. Ministério da Educação. Secretaria de Educação Fundamental. Brasília, 1997.

FILHO, Geraldo Inácio; NUNES, Silma do Carmo. A pesquisa no Ensino Fundamental. Ensino em Re-vista, v.7, n.1, 95-112, jul.98/jun.99. Disponível em: http://www.seer.ufu.br/index.php/emrevista/article/view/7851. Acesso em 16 de jan. de 2012.

FREIRE, P. Pedagogia da autonomia: saberes necessários à prática educativa. São Paulo: Paz e Terra, 1996.

GATTI, Bernadete Angelina. A construção da pesquisa em educação no Brasil. . Série Pesquisa em Educação, v.1, Brasília: Plano Editora, 2002.

HERNÁNDEZ, Fernando. Transgressão e mudança na educação: os projetos de trabalho. Porto Alegre: artmed, 1998.

Pensar a Prática, Goiânia, v. 17, n. 2, p. 331-343, jan./mar. 2014 
KUHLTHAU, Carol Collier. Como orientar a pesquisa escolar: estratégias para o processo de aprendizagem. Belo Horizonte: Autêntica Editora, 2010.

LIBÂNEO, José Carlos. Democratização da escola pública: a pedagogia crítico-social dos conteúdos. São Paulo: Loyola, 2005.

LÜDKE, M. et al. O que conta como pesquisa? São Paulo: Cortez, 2009.

MORAES, R. et al. Pesquisa em sala de aula: fundamentos e pressupostos. In: MORAES, R.; LIMA, V. M. R. (Org.). Pesquisa em sala de aula: tendências para a educação em novos tempos. Porto Alegre: EDIPUCRS, 2004.

NICOLINI, Cristiane Antonia H. Projetos de aprendizagem e educar pela pesquisa como prática de cidadania. 139 p. Dissertação (Mestrado em Ciências e Matemática). Pontifícia Universidade Católica do Rio Grande do Sul, 2005.2 Disponível em: www.cipedya.com/web/FileDownload.aspx?IDFile=160749. Acesso em 4 de fev. de 2012.

NININ, Maria Otilia Guimarães. Pesquisa na escola: que espaço é esse? O do conteúdo ou o do pensamento crítico? Educação em Revista, v. 0 , n, 48, p.p- 15-35, Dez, 2008. Disponívelem:http://www.scielo.br/scielo.php?pid=S01024698200800 0200002\&script=sci_arttext. Acesso em 18 de jan. de 2012.

PÁDUA Elisabete Matallo Marchesini de. Metodologia da pesquisa: Abordagem teórico prática. Campinas: Papirus, 1996.

SAVIANI, Dermeval. Escola e democracia: teorias, curvatura da vara, onze teses sobre a educação e política. São Paulo:Cortez; Autores Associados, 2009. - (coleção Polêmicas do nosso tempo, 5).

STEFANO, Leizy Regina Fracasso. Representações de professores e alunos sobre a pesquisa escolar: a leitura crítica, a escrita autônoma e a formação do conhecimento. 127 p. Dissertação (Mestrado em Letras). Universidade Estadual de Maringá, 2005. Disponível em: http://www.ple.uem.br/defesas/pdf/lrfstefano.pdf. Acesso em 17 de nov. de 2011.

Pensar a Prática, Goiânia, v. 17, n. 2, p. 331-343, jan./mar. 2014 343 
Recebido em: 18/04/2013

Revisado em: 09/09/2013

Aprovado em: 11/09/2012

Endereço para correspondência:

davilajorgeluis35@gmail.com

Jorge Luis D"Avila

Universidade Federal de Mato Grosso do Sul

Cidade Universitária

Universitário - CEP: 79070-900

Pensar a Prática, Goiânia, v. 17, n. 2, p. 331-343, jan./mar. 2014 